\title{
A Multi-channel Anechoic Orchestra Recording of Beethoven's Symphony No. 8 op. 93*
}

\author{
CHRISTOPH BÖHM, DAVID ACKERMANN, AND STEFAN WEINZIERL \\ (c.boehm@tu-berlin.de) (david.ackermann@tu-berlin.de) (stefan.weinzierl@tu-berlin.de)
}

Audio Communication Group, TU Berlin, Germany

\begin{abstract}
For the quality of model-based, virtual acoustic environments, not only the room acoustic simulation but also the quality and suitability of the source material play an important role. An optimal recording of real sound sources is characterized by an anechoic production and a high signal-to-noise ratio and crosstalk attenuation between the different recording channels. Furthermore a recording in the far field of the source is necessary to use correct directivities for room acoustic simulations. From an artistic point of view, the recording situation with its technical boundary conditions must be designed in a way that the musical or vocal rendering of professional performers is impaired as little as possible. To provide a high-quality source signal for acoustic simulations of orchestral content, a professional symphony orchestra was recorded in the anechoic chamber of TU Berlin performing the 8th Symphony of L. v. Beethoven. Through a combination of groupwise and sequential recordings with individual monitor mixes via headphones and video recordings of the conductor and concertmaster, an optimal compromise was sought with regard to artistic and technical aspects. The article presents the recording process and processing chain as well as the results achieved with respect to technical and artistical quality criteria.
\end{abstract}

\section{INTRODUCTION}

The auralization of data-based or model-based virtual acoustic environments has a variety of applications from acoustical and electro-acoustical planning [1] to room acoustic and psychoacoustic research [2,3], music research [4], game audio [5], or virtual acoustic reality in general [6]. Even historical locations that no longer exist can be reconstructed, acoustically analyzed, and experienced again in this way [7-9].

For the quality of an auralization, not only the room acoustic simulation is a challenge that has so far only been partially met [10], but also the production of suitable audio content. From a technical point of view, the sound sources for auralizations should be recorded in an anechoic environment, with a high signal-to-noise ratio and a low crosstalk between the different sound sources and corresponding recording channels. At the same time, a recording in the far field of the source is necessary if correct directivities for the room acoustic simulation are to be used. And finally, the recording situation with its technical boundary conditions must be designed in a way that the musical or vocal

*Correspondence should be addressed to Stefan Weinzierl. Email: stefan.weinzierl@tu-berlin.de rendering of professional performers is impaired as little as possible.

Most existing anechoic orchestral recordings [11-15] have certain limits in terms of technical and/or artistic quality due to the challenges mentioned above and the compromises that are required. In addition, with the exception of [15], the string sections of the related orchestras were not recorded with the complete number of voices, so that a small number of tracks has to be technically duplicated in order to auralize a symphonic performance with typically 12 to 16 first violins. Therefore a new anechoic production of a professional symphony orchestra was conducted at TU Berlin.

The Orchester Wiener Akademie conducted by Martin Haselböck was invited to perform the 8th Symphony of L. $v$. Beethoven in the anechoic chamber. The orchestra plays in historically informed performance practice, using historical originals or replicas as music instruments. With a special interest in the specific acoustic conditions of historical music venues of the Viennese Classicism and their digital reconstructions [16], the orchestra also had experience with the special conditions of film music production, such as ensemble playing with headphone monitoring and recording via a mixed pilot track during the recording.

The first, second, and fourth movements of the 8th Symphony of L. v. Beethoven, op. 93 were recorded, with a 
Table 1. Recorded instruments, number of musicians, and final number of recorded voices per instrument.

\begin{tabular}{llll}
\hline Instrument & Musicians & Voices & Group \\
\hline 1. Violin & 2 & 14 & Strings \\
2. Violin & 2 & 11 & \\
Viola & 2 & 11 & \\
Violoncello & 1 & 6 & \\
Double Bass & 1 & 6 & Woodwinds \\
\hline Flute & 2 & 2 & \\
Oboe & 2 & 2 & \\
Clarinet & 2 & 2 & Brass \\
Bassoon & 2 & 2 & Percussion \\
\hline Horn & 2 & 2 & \\
Trumpet & 2 & 2 & \\
\hline Timpani & 1 & 1 & $\mathbf{6 1}$ \\
\hline$\sum$ & $\mathbf{2 1}$ & & \\
\hline
\end{tabular}

total playing time of 20 minutes. The number of recorded tracks corresponds to a medium-sized orchestral instrumentation (Table 1). Crosstalk could be reduced to a minimum by a groupwise, semi-sequential recording of the instruments. In order to enable exact timing for the musicians, a video recording of the conductor and the concertmaster was played on individual screens in the recording room in addition to an individual monitor mix via headphones. To achieve a music production with industry standard production quality, a professional recording supervisor conducted the recording and post-production of the audio material. An excerpt of the audio content with all necessary metadata for its use in high-quality auralizations is available under the license CC BY 4.0 [17].

\section{PRODUCTION}

The orchestra was recorded in the anechoic chamber of the TU Berlin. With a room volume of $1,070 \mathrm{~m}^{3}$, a lower cut-off frequency of $63 \mathrm{~Hz}$, and a walk-in area on a wire net of $112 \mathrm{~m}^{2}$, it offers sufficient space for polyphonic music recordings.

\subsection{RECORDING ENVIRONMENT}

The musicians were placed standing or sitting on the net. In order to achieve optimum separation between the instruments, shielding screens were suspended from a specially installed truss rig due to the limited mechanical strength of the walk-in wire net. Solid wooden walls covered with 20 $\mathrm{cm}$ thick foam material were used as absorbing partitions. In order to prevent multiple reflections, these were hung at a slight angle to each other. This made it possible to create half-open recording booths for eight musicians playing simultaneously (Figs. 1 and 2).

\subsection{RECORDING SETUP}

The microphones were arranged in such a way that on the one hand a high crosstalk attenuation toward other instru- ments was achieved, and on the other hand a position favorable for the tonal quality of the instrument was realized, meeting the demands of the professional sound engineers responsible.

To achieve an optimal channel separation, the cellos and basses were recorded with cardioid microphones, while for all other instruments, microphones with a figure-of-eight characteristic were used. Only for the timpani a pressure transducer was used because it was recorded alone in the room. For the signal path with lowest separation (cf. Tab. 2), a crosstalk attenuation of about $10 \mathrm{~dB}$ at $100 \mathrm{~Hz}$ increasing to $30 \mathrm{~dB}$ at $1 \mathrm{kHz}$ was achieved between the microphone directly at the source and the next nearest microphone (Fig. 3), with a broadband crosstalk attenuation of at least $-26.7 \mathrm{~dB}$ if the frequency weighting of a simulated program signal according to IEC 60268-1 [18] is applied.

This value was shown to be sufficient to avoid both audible coloration [19] and a localization shift compared to the primary source and thus seems high enough for auralization of an instrumental group recorded in parallel. The results of a crosstalk attenuation analysis for all source and all recording positions of the recording setup of the string group are shown in Table 2.

The frequency responses and transmission factors of all microphones were determined, as well as the gain of the microphone preamps during recording. All figure-of-eight and omnidirectional microphones were directed from above toward the main sound radiating area of each instrument. When the microphones were aligned, care was also taken to ensure that the sound reflection of the monitors had minimal impact on the recording channel with the help of the chosen directional characteristic of the microphones. The cardioid microphones for cello and double bass, for example, were placed in front of the instrument between the musician and monitor, so that the direction of the greatest cancellation was directed toward the monitor.

The microphone types used and the exact microphone positions in spherical coordinates (azimuth and elevation relative to the head of the musician) are given in Table 3 and are included in the data set. For acoustic decoupling from the wire net, the microphones were suspended on cords from the truss construction, thus avoiding the transmission of structure-borne noise.

During the entire recording attention was paid to an optimal level control, using high-quality preamplifiers and A/D converters (PreSonus DigiMax DP88, RME UFX) with a $48 \mathrm{kHz}$ sampling rate and 32 bit word width in floatingpoint format. The final level ratios between the individual tracks are taken into account in the files without affecting the SNR. Due to the recording in the described format, a level close to $0 \mathrm{~dB}$ full scale is not necessary.

\subsection{MONITORING}

Due to the spatial separation of the simultaneously playing instrumentalists from each other and the groupwise recording, special attention had to be paid to a musically accurate timing and good intonation as well as a low latency recording environment for the musicians. For this purpose, 


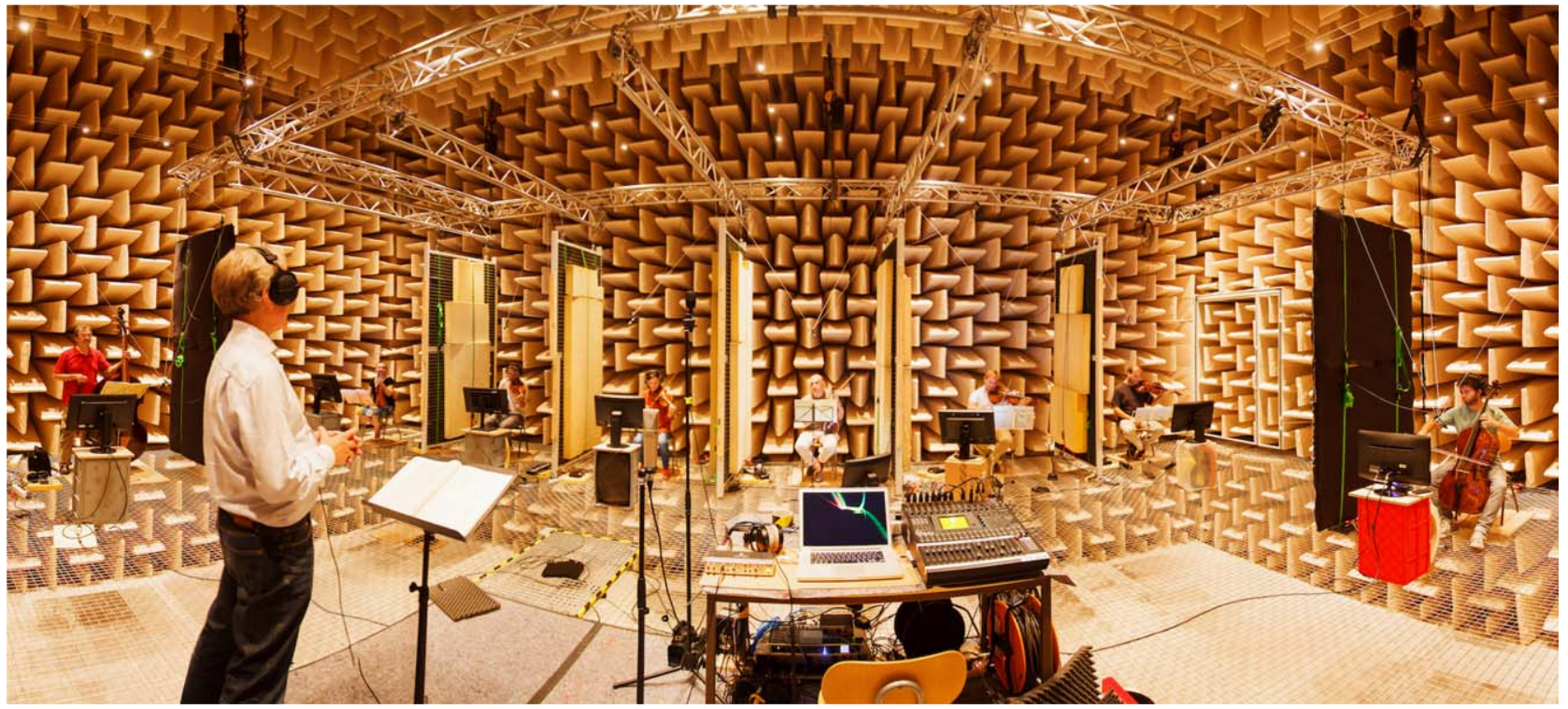

Fig. 1. Recording situation in the anechoic chamber of the TU Berlin with eight musical instruments and a conductor, also showing the monitor mixing desk.

a pilot track of the first string group $(2 \mathrm{x} v \mathrm{vn}, 2 \mathrm{x}$ vn2, $2 \mathrm{x}$ va, $1 \mathrm{x} \mathrm{vc}, 1 \mathrm{x} \mathrm{db}$ ) led live by the conductor was recorded in the first round of recordings. In addition to the audio recording, two video cameras were used to record the conductor and the concertmaster. The pilot track and associated video recordings were played back synchronously for all other groups of the musicians via headphones and displays. This allowed the musicians to follow the conductor as well as the bow of the concertmaster while playing with their group. For the video playback, a split-screen view of both videos was shown on video monitors for each of the up to eight musicians in one group.

The mutual listening in the unfamiliar environment of the anechoic chamber was realized by a stereophonic monitoring for each of the musicians via headphones. For this purpose, the input signals of the microphones were sent via a digital direct out to the monitor mixer immediately after amplification. An individual mix was created for each musician from his or her own direct sound and the other current voices as well as the voices already recorded. In ad-

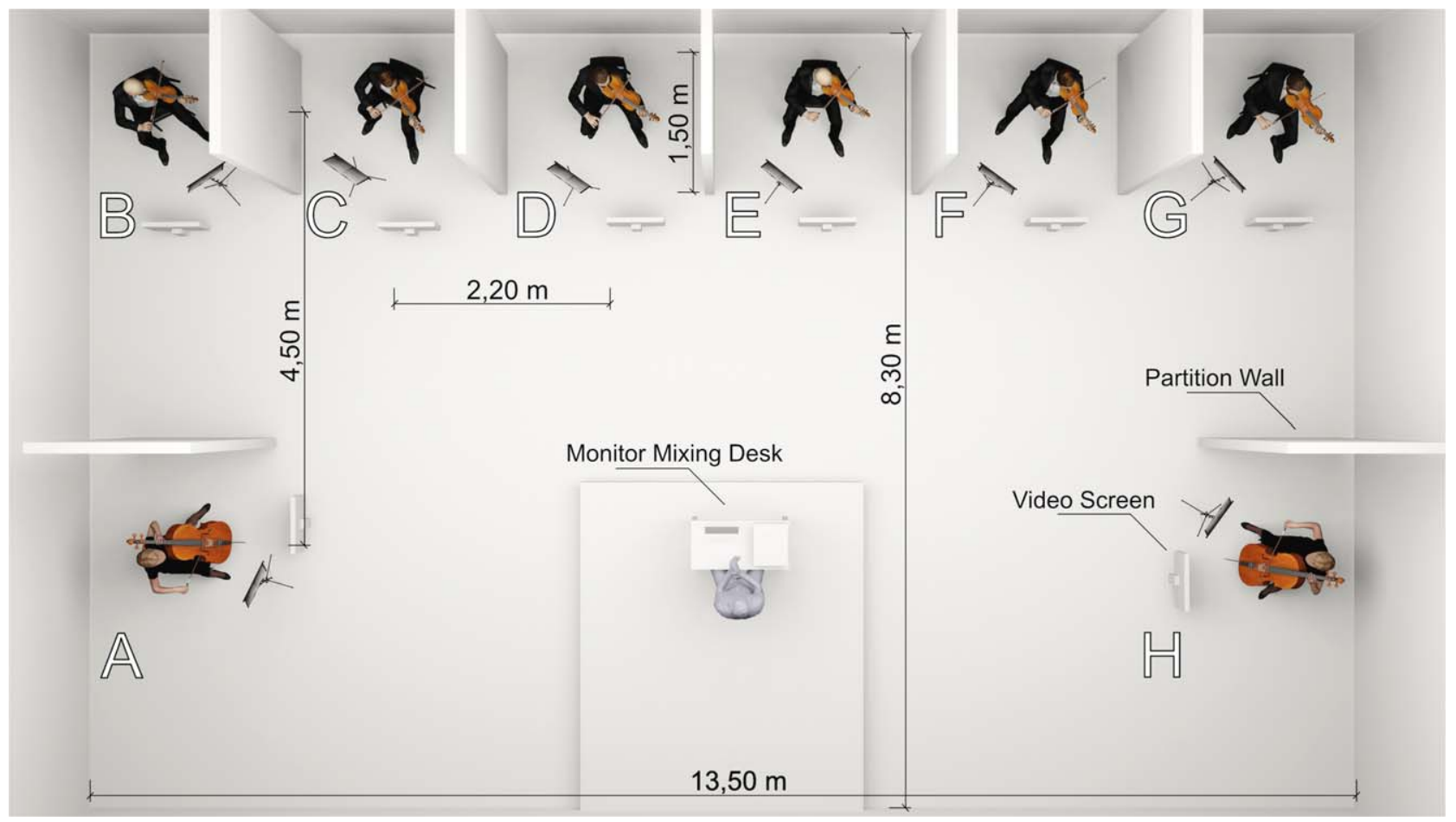

Fig. 2. Recording setup in the anechoic chamber of the TU Berlin with eight instruments and a monitor mixing desk. 
Table 2. Frequency weighted crosstalk attenuation in dB assuming a simulated program signal according to IEC 60268-1 [18] for all source and recording positions of the recording setup of the string group. The bold printed value shows the lowest crosstalk attenuation of this analysis; a further frequency-dependent evaluation of this particular source-receiver configuration is shown in Fig. 3. Missing data is marked with an *.

\begin{tabular}{ccccccrrr}
\hline Source Position & \multicolumn{7}{c}{ Recording Position } & \\
\hline & A & B & C & D & E & F & G & H \\
A & - & -39.1 & -37.4 & -35.5 & -38.4 & -34.7 & -34.9 & -38.8 \\
B & -37.2 & - & -27.7 & -34.3 & -40.3 & -37.5 & -37.2 & -40.3 \\
C & -40.0 & -29.6 & - & -28.2 & -38.4 & -36.6 & -36.5 & -39.6 \\
D & -40.8 & -38.3 & -30.4 & - & -32.3 & -35.1 & -36.7 & -40.1 \\
E & -42.3 & -38.3 & -35.7 & -26.7 & - & -28.9 & -33.4 & -35.2 \\
F & -45.3 & -41.8 & -40.2 & -36.6 & -34.0 & - & -31.2 & -36.5 \\
G & -47.1 & -42.6 & -41.3 & -38.8 & -41.0 & $*$ & - & -34.6 \\
H & -39.2 & -41.2 & -38.1 & -37.3 & -40.7 & $*$ & -38.0 & - \\
\hline
\end{tabular}

dition, a convolution reverb with a simulated binaural room impulse response suitable for orchestral performances was used to create a natural acoustic recording environment for the musicians. Since the monitoring of each performer's own instrument is particularly time-critical, impulse responses without direct sound were used and convolved with the instrument signal on a computer and added to the dry signal, which was then sent directly from the mixing console with negligible latency to the headphone amplifiers used.

\subsection{RECORDING WORKFLOW}

Through groupwise, semi-sequential recording of the orchestra, an optimal compromise was aimed at with regard to artistic and technical aspects. Up to eight voices were recorded simultaneously in the room. The four orchestral groups, i.e., strings, woodwinds, brass, and percussion (see Table 1), were recorded one after the other. In order to create a medium-sized orchestra, the string section was recorded six times in a row. In addition, individual passages could be recorded several times and sequentially for digital editing.

The recording was led by a musical recording supervisor and the conductor. In a first run, passages that were not artistically successful were repeated until a satisfactory version for all participants was reached.

\subsection{POST PROCESSING}

When processing the recorded audio signals, the changes in the microphone gain documented during recording were first compensated. The recorded takes were then edited and merged, thereby correcting slight asynchronies between the individual tracks.

Table 3. Microphones used and their positions relative to the instrument, in the spherical coordinates azimuth $\phi$, elevation $\theta$, and radial distance $r$. A detailed description of the coordinate system used is shown in Fig. 5.

\begin{tabular}{|c|c|c|c|c|c|c|c|c|c|}
\hline \multirow[t]{2}{*}{ Instrument } & \multirow[t]{2}{*}{$\begin{array}{l}\text { Recording } \\
\text { Position }\end{array}$} & \multirow[t]{2}{*}{ Mic (Nr.) } & \multirow[t]{2}{*}{$\begin{array}{l}\text { Mic } \\
\text { Directivity }\end{array}$} & \multicolumn{3}{|c|}{ Mic Position } & \multirow[t]{2}{*}{$\begin{array}{l}\text { Mic Gain } \\
\text { in } \mathrm{dB}\end{array}$} & \multirow[t]{2}{*}{$\begin{array}{l}\text { Artistic } \\
\text { Gain in } \mathrm{dB}\end{array}$} & \multirow[t]{2}{*}{$\begin{array}{l}\text { HP Filter } \\
\text { in } \mathrm{Hz}\end{array}$} \\
\hline & & & & $\phi$ in deg & $\theta$ in deg & $r$ in $\mathrm{m}$ & & & \\
\hline Violin 1.1 & $\mathrm{E}$ & KM 120 (1) & Eight & 12 & 62 & 0.61 & 40 & -12 & 180 \\
\hline Violin 1.2 & $\mathrm{C}$ & KM 120 (2) & Eight & 30 & 55 & 0.81 & 40 & -6 & 180 \\
\hline Violin 2.1 & $\mathrm{D}$ & KM 120 & Eight & 68 & 59 & 0.83 & 40 & -6 & 180 \\
\hline Violin 2.2 & $\mathrm{~B}$ & KM 120 (4) & Eight & 0 & 69 & 0.65 & 40 & -6 & 180 \\
\hline Viola 1 & $\mathrm{~F}$ & KM 120 (5) & Eight & 9 & 66 & 0.89 & 40 & -12 & 120 \\
\hline Viola 2 & $\mathrm{G}$ & KM $120(6)$ & Eight & 39 & 58 & 0.88 & 40 & -12 & 120 \\
\hline Cello & $\mathrm{H}$ & KM 184 (7) & Cardioid & 0 & -19 & 0.52 & 30 & -6 & 60 \\
\hline D. Bass & A & KM 184 (8) & Cardioid & 22 & -14 & 0.55 & 30 & -2 & 40 \\
\hline Bassoon 1 & $\mathrm{D}$ & KM 120 (3) & Eight & -28 & 51 & 0.86 & 40 & -12 & 50 \\
\hline Bassoon 2 & B & KM 120 (4) & Eight & 0 & 40 & 0.78 & 40 & -14 & 50 \\
\hline Flute 1 & $\mathrm{C}$ & KM 120 (2) & Eight & -35 & 49 & 0.61 & 40 & -17 & 240 \\
\hline Flute 2 & A & MK 8 (9) & Eight & -81 & 39 & 0.8 & 40 & -18 & 240 \\
\hline Clarinet 1 & $\mathrm{E}$ & KM 120 (1) & Eight & 35 & 23 & 0.79 & 40 & -16 & 140 \\
\hline Clarinet 2 & $\mathrm{G}$ & KM $120(6)$ & Eight & 0 & 39 & 0.88 & 40 & -15 & 140 \\
\hline Oboe 1 & $\mathrm{~F}$ & KM $120(6)$ & Eight & 0 & 20 & 0.85 & 40 & -15 & 220 \\
\hline Oboe 2 & $\mathrm{H}$ & MK 8 (10) & Eight & 6 & 56 & 0.71 & 40 & -15 & 220 \\
\hline Trumpet 1 & $\mathrm{E}$ & KM $120(1)$ & Eight & 31 & 19 & 1.61 & 30 & -7 & 180 \\
\hline Trumpet 2 & $\mathrm{G}$ & KM 120 (6) & Eight & 38 & 30 & 0.91 & 30 & -7 & 180 \\
\hline Horn 1 & $\mathrm{C}$ & KM 120 (2) & Eight & -134 & 36 & 0.65 & 30 & -14 & 50 \\
\hline Horn 2 & $\mathrm{~A}$ & MK 8 (9) & Eight & -118 & 62 & 0.58 & 30 & -17 & 50 \\
\hline Timpani & - & MK 5 (11) & Omni & 0 & 80 & 1.18 & 15 & -7 & 40 \\
\hline
\end{tabular}




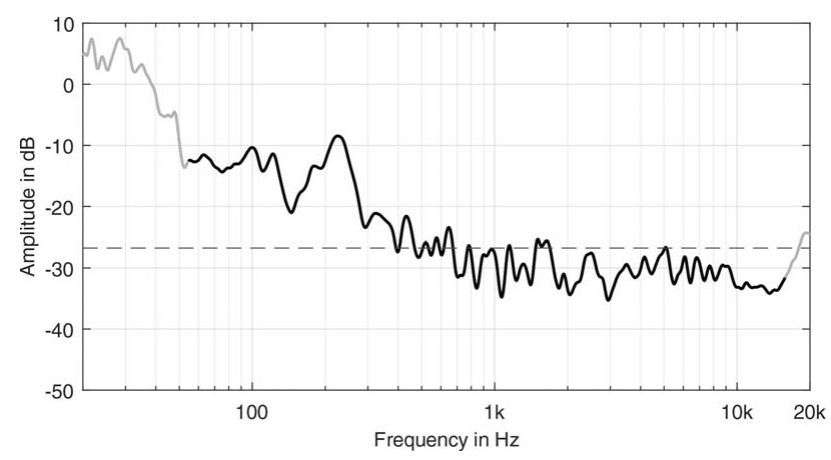

Fig. 3. Crosstalk attenuation between 2 adjacent microphones, illustrated by the frequency response of the Neumann KM 120 (3) microphone used for the recording of Violin 2.1 at recording position D and a Genelec 8020c loudspeaker placed at recording position $\mathrm{E}$, at a distance of $1 \mathrm{~m}$ from the microphone that was used for the recording of Violin 1.1 and directed toward the ceiling. The shown frequency-dependent crosstalk was referenced to the corresponding frequency response of the Neumann KM 120 (1) microphone at recording position $\mathrm{E}$. The dashed line shows the frequency weighted crosstalk attenuation assuming a simulated program signal according to IEC 60268-1 [18]. Considering the bandwidth of the sound source used, only the range between 50 $\mathrm{Hz}$ and $15 \mathrm{kHz}$ was used for the calculation (black), and the side bands (gray) were discarded.

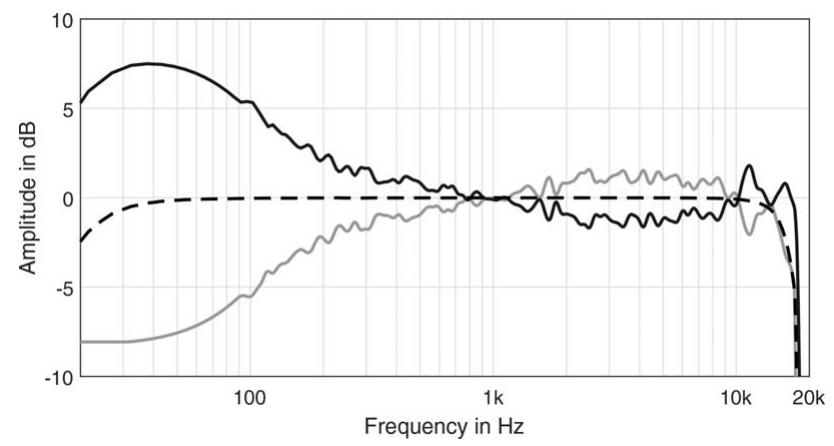

Fig. 4. Transfer function (gray) and inverse filter (black) for a Neumann KM120 microphone; the dashed line shows the compensation result of the inverse filter on the transfer function.

Filters were generated from the on-axis frequency responses of each individual microphone, which were previously measured in the anechoic chamber at Georg Neumann $\mathrm{GmbH}$ in Berlin. Regularized least mean squares (LMS) inversion with a regularization function generated from a high-shelf filter with its characteristic frequency@16 kHz was used to design the inverse filters for the microphone transfer function [20, function: AKregulatedInversion()], which was applied as minimal phase FIR to the final audio tracks to compensate for the influence of the microphones on the frequency response (see example in Fig. 4).

The level differences due to different distances between microphone and instrument were also compensated as well as the measured microphone sensitivities. For this purpose, all tracks were normalized to the sensitivity of the Schoeps MK 5, used for the recording of Timpani, the microphone with the lowest sensitivity of $10.1 \mathrm{mV} / \mathrm{Pa} @ 1 \mathrm{kHz}$, and to a distance of $1 \mathrm{~m}$. To minimize crosstalk and suppress low frequency noise in the recording, the tracks were processed with a Butterworth high pass filter of order 4 , adjusting the cutoff frequency for each instrument individually so that the lowest playable tone was not affected and thus the full bandwidth of the instrument was preserved (see Tab. 3: HP Filter).

In order to consider the different levels of the instruments, the preamplifiers were set differently during recording. The corresponding mic gains can be found in Table 3. To achieve a uniform amplification for all instruments, the differences in these gains can be adjusted to each other.

In a final step, an artistic adjustment of the levels was carried out. Even if the microphone distances and sensitivities were compensated in the final audio tracks, a final adjustment can be useful because the dynamic adjustment of the performers within an instrument group in a familiar acoustic environment is not possible in the same way with headphones in an anechoic room, leading to a dynamically slightly inhomogeneous balance between the individual voices. This final adjustment of the levels was carried out by a professional sound engineer. The level changes are documented (Tab. 3) and can be reversed if necessary.

Since all tracks were normalized to a microphone distance of $1 \mathrm{~m}$ and to a microphone sensitivity of $10.1 \mathrm{mV} / \mathrm{Pa}$, the sound pressure level of Flute 1 at $1 \mathrm{~m}$, for example, can be calculated as follows: a sound pressure level of $94 \mathrm{~dB}$ SPL corresponds to a microphone output level of -37.8 $\mathrm{dBu}(10.1 \mathrm{mV} / \mathrm{pa})$. The KM 120 Neumann microphone has been amplified by $40 \mathrm{~dB}$ to $2.2 \mathrm{dBu}$ (refer to Tab. 3: Mic gain), which results in a level of the AD converters of -9.8 dBFs (the Digimax DP88 analog-to-digital converter has a sensitivity of $+12 \mathrm{dBu} @ 0 \mathrm{dBFs})$. Finally, the signal was reduced by $-17 \mathrm{~dB}$ by a sound engineer's processing (see Tab. 3: Artistic gain), and thus a level of $-26.8 \mathrm{dBFs}$ in the audio signal corresponds to a sound pressure level of 94 $\mathrm{dBSPL}$ at $1 \mathrm{~m}$ distance from the recorded sound source in the direction of the microphone.

\section{RESULTS AND DISCUSSION}

The result of the production described above is the first, second, and fourth movement of the 8th Symphony op. 93 by Ludwig van Beethoven, with a duration of 8:11, 4:08, and 7:24 minutes. The dataset contains 61 single tracks for each instrumental voice as well as a stereo mix with artificial reverberation to get a first impression of the artistic quality and the potential of the recordings. Excerpts of ca. 1:00 minute length are published under open access with a license of CC BY 4.0. For further use of the complete recording, please contact the authors of the article.

The microphone frequency compensation filters used are contained in the form of impulse responses in WAV format. These were derived from the measured on-axis frequency response for each individual microphone. We analyzed the error resulting from the fact that the sound source was either not exactly in the $0^{\circ}$ direction of the microphone or that the musical instrument is an extended sound source, which is true, for example, for string instruments, where the entire 


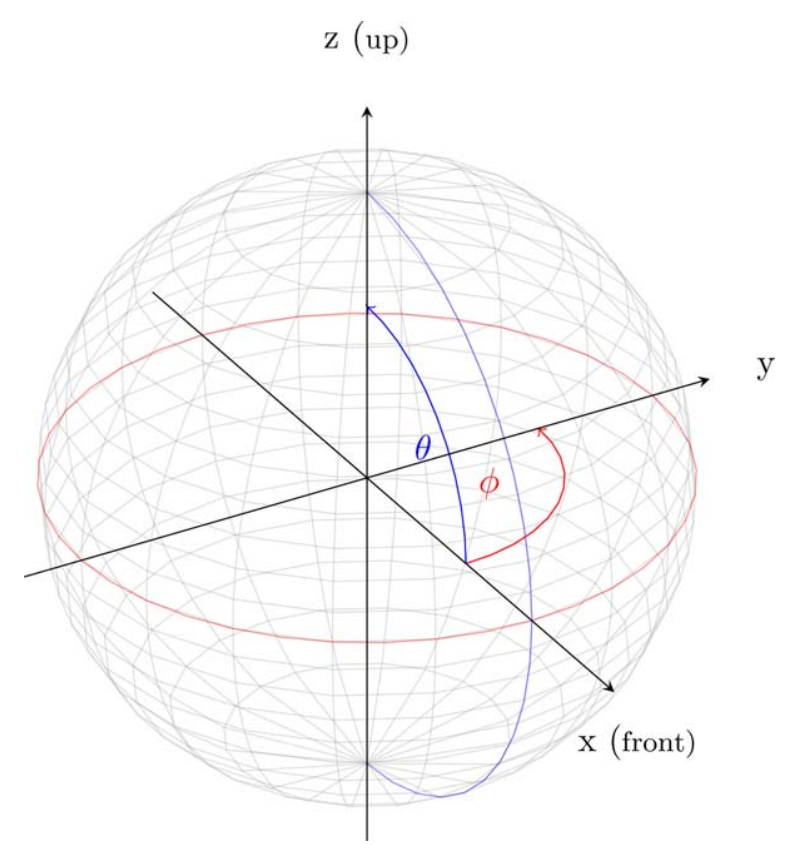

Fig. 5. Coordinate system for the documentation of the microphone positions.

soundboard is radiating sound. If we assume that the major sound radiating parts of the musical instruments involved are within a dimension of $30 \mathrm{~cm}$, this leads to angles of \pm $8.5^{\circ}$ from the center of the source for a recording distance of $1 \mathrm{~m}$. Considering the difference of the frequency responses for $0^{\circ}$ and $10^{\circ}$, for example, for the KM184 microphone used, leads to differences $<0.2 \mathrm{~dB}$ for all $1 / 3$-octave bands up to $12.5 \mathrm{kHz}$. The error introduced for sound sources of this size thus appears to be negligible, also for the other small diaphragm microphones used, whose increase in directivity begins only at very high frequencies.

The exact microphone positions are given in spherical coordinates, i.e., in azimuth $\left(\phi=0^{\circ}\right.$ pointing in positive $\mathrm{x}$-direction, $\phi=90^{\circ}$ pointing in positive y-direction), elevation $\left(\theta=0^{\circ}\right.$ pointing in positive $\mathrm{x}$-direction, $\theta=90^{\circ}$ pointing in positive $\mathrm{z}$-direction), and distance (in meter) for each instrument (cf. Tab. 3). The origin of the coordinate system corresponds to the head position of the musicians. Thus, the origin is $1.2 \mathrm{~m}$ above the ground, the average ear position for seated people on a $0.45 \mathrm{~m}$ high chair [21]. The musicians' viewing direction is along the $\mathrm{x}$-axis (see Fig. 5).

The microphone positions were chosen to obtain audio recordings preserving the tone color of the musical instrument as experienced in a natural environment while at the same time providing sufficient crosstalk attenuation for other instruments. These positions were thus sometimes slightly different from the positions traditionally used in recordings of classical music. For use in auralizations, however, neither traditional nor modified positions should be used without compensation.

This compensation can be achieved by using the microphone positions to normalize the instrument directivities, such as those measured at TU Berlin with a spherical ar- ray of 32 microphones [22, 23], to the direction of the microphone during recording or by equalizing the audio content with the inverse frequency response of the source directivity at this point. Both approaches make sure that the sound pressure at the microphone position will be unaffected by the source directivity in the simulation, while all other directions of sound radiation have correct frequency weighting.

By doing so, deviations resulting from unusual microphone positions relative to the sound at more traditional recording positions will also be compensated accordingly. Only very unfavorable positions, e.g., with a strong damping of high frequencies, can lead to problems with the signal-to-noise ratio after compensation. This was, however, not the case in the current recording.

As an additional measure, an "artistic gain" was introduced to the individual tracks by a professional sound engineer who created a balanced stereo mix with artificial reverb according to artistical criteria. This gain compensates for the individual dynamic performance of the musicians as well as for the different sound powers of the instruments [24], which are in a concert performance affected by a specific, distance-related attenuation and lets, for example, the woodwinds appear softer than the strings in front. For applications creating a mix of the anechoic material itself with or without artificial reverb, we recommend adopting these gains. If, however, a room acoustic auralization is conducted, with impulse responses that already contain a distance-related attenuation, the general gain reduction indicated, e.g., for the woodwinds, should not be applied. In this case, only the gain alignment within an instrument group can be used. If the impulse responses do not contain distance-related attenuations (because certain room acoustical simulation softwares, for example, always provide normalized impulse responses), we recommend either adopting the artistic gains or defining a reference listening position and calculating the distance-related attenuations at this position by hand.

It should be noted that the additional artistic adjustment of the levels also influences the corresponding crosstalk attenuation, reducing the attenuation for some signal paths and increasing it for others (cf. Tab. 2). For the group of strings and brass the range of artistic attenuation is $10 \mathrm{~dB}$ and for the group of woodwinds only $6 \mathrm{~dB}$. Thus the crosstalk attenuation never falls below a value of -20.7 $\mathrm{dB}$, which is still in the acceptable range to avoid both audible coloration [19] and a localization shift compared to the primary source.

The published anechoic audio production should make it possible to estimate the acoustic effect of musical performance spaces for orchestral works through the auralization of a high-quality performance of a piece frequently played in the symphonic concert repertoire already in the planning phase.

Considering the results of the recording, the production method turned out to be a good compromise. On the one hand, it provides the technical characteristics required for room acoustic auralizations, while at the same time giving the artists a minimum of acoustic feedback and allowing 
them, at least within their instrumental group, to make music together, which the invited orchestra considered to be essential for an artistically convincing symphonic ensemble performance.

The documentation of the recording follows the DEGA memorandum for the execution and documentation of audio productions for scientific applications in acoustics [25].

\section{ACKNOWLEDGMENT}

We thank the musicians of the Orchestra Wiener Akademie: Ilia Korol, Irma Niskanen, David Drabek, AnnaMaria Smerd (violins), Pablo de Pedro Cano and Wolfram Fortin (violas), Philipp Comploi (violoncello), Walter Bachkönig (double bass), Verena Fischer and Charles Brink (flutes), Sebastian Frese and Shai Kribus (oboes), Peter Rabl and Christian Köll (clarinets), Takako Kunugi and Laszlo Feriencsik (bassoons), Hermann Ebner and Ferenc Varga (French horns), Stefan Ennemoser and Sigfried Koch (trumpets), and Paul Bramböck (timpani). Special thanks for his open-mindedness for this acoustic experiment go to the conductor Martin Haselböck. Moreover we thank Ruben Ferdinand (recording supervisor), Balthasar Effmert (digital editing), Clémence Fabre, Philipp Reif, Hannes Helmolz and Dmitry Grigoriev (assistant engineers), and Georg Neumann $\mathrm{GmbH}$ and Sennheiser $\mathrm{GmbH}$ \& Co. KG (Martin Schneider) for providing recording equipment.

\section{REFERENCES}

[1] H. Kuttruff, "Digital Simulation of Concert Hall Acoustics and Its Applications," Acoust. Bull., vol. 16, no. 5, pp. 5-8 (1991).

[2] T. Lokki, "Subjective Comparison of Four Concert Halls Based on Binaural Impulse Responses," Acoust. Sci. \& Tech., vol. 26, no. 2, pp. 200-203 (2005).

[3] S. Weinzierl, S. Lepa, and D. Ackermann, "A Measuring Instrument for the Auditory Perception of Rooms: The Room Acoustical Quality Inventory (RAQI)," J. Acoust. Soc. Am., vol. 144, no. 3, pp. 1245-1257 (2018 Sept.), https://doi.org/10.1121/1.5051453.

[4] Z. Schärer Kalkandjiev and S. Weinzierl, "The Influence of Room Acoustics on Solo Music Performance: An Experimental Study," Psychomusicol. Music Mind Brain, vol. 25, no. 3, pp. 195-207 (2015), https:// doi.org/10.1037/pmu0000065.

[5] C. Schissler, A. Nicholls, and R. Mehra, "Efficient HRTF-Based Spatial Audio for Area and Volumetric Sources," IEEE Trans. Visual. Comput. Graph., vol. 22, no. 4, pp. 1356-1366 (2016 Apr.), https://doi.org/10.1109/ TVCG.2016.2518134.

[6] M. Vorländer, Auralization: Fundamentals of Acoustics, Modelling, Simulation, Algorithms and Acoustic Virtual Reality, 1st ed. (Springer, Berlin, Heidelberg, Germany, 2008), https://doi.org/10.1007/978-3-540-48830-9.

[7] J. H. Rindel, "Room Acoustic Modelling Techniques: A Comparison of a Scale Model and a Com- puter Model for a New Opera Theatre," Build. Acoust., vol. 18, no. 3-4, pp. 259-280 (2011 Dec.), https:// doi.org/10.1260/1351-010X.18.3-4.259.

[8] S. Weinzierl, P. Sanvito, F. Schultz, and C. Büttner, "The Acoustics of Renaissance Theatres in Italy," Acta Acust. united Acust., vol. 101, no. 3, pp. 632-641 (2015 May/Jun.).

[9] V. Lombardo, A. Valle, J. Fitch, K. Tazelaar, S. Weinzierl, and W. Borczyk, "A Virtual-Reality Reconstruction of Poème Électronique Based on Philological Research," Comput. Music J., vol. 33, no. 2, pp. 24-47 (2009 Jun.).

[10] F. Brinkmann, L. Aspöck, D. Ackermann, S. Lepa, M. Vorländer, and S. Weinzierl, "A Round Robin on Room Acoustical Simulation and Auralization," J. Acoust. Soc. Am., vol. 145, no. 4, pp. 2746-2760 (2019 Apr.), https://doi.org/10.1121/1.5096178.

[11] A. N. Burd, "Nachhallfreie Musik für Akustische Modelluntersuchungen," Rundfunktechnische Mitteilungen, vol. 13, pp. 200-201 (1969).

[12] I. B. Witew, J. Paprotny, and G. K. Behler, "Auralization of Orchestras in Concert Halls Using Numerous Uncorrelated Sources," Proc.Inst. Acoust., vol. 28, pt. 2, pp. 293-296 (2006).

[13] J. Pätynen, V. Pulkki, and T. Lokki, "Anechoic Recording System for Symphony Orchestra," Acta Acust. United Acust., vol. 94, no. 6, pp. 856-865 (2008 Nov./Dec.), https://doi.org/10.3813/AAA.918104.

[14] M. C. Vigeant, L. M. Wang, J. H. Rindel, C. L. Christensen, and A. C. Gade, "Multi-Channel Orchestral Anechoic Recordings for Auralizations," Architect. Eng. Faculty Pub., vol. 4 (2010).

[15] D. D'Orazio, "Anechoic Recordings of Italian Opera Played by Orchestra, Choir, and Soloists," J. Acoust. Soc. Am., vol. 147, no. 2, pp. EL157-EL163 (2020).

[16] C. Brown, "Re-Sound Beethoven," NineteenthCent. Music Rev., vol. 14, no. 1, pp. 133-137 (2017 Apr.).

[17] C. Böhm, D. Ackermann, and S. Weinzierl, "A Multi-Channel Anechoic Orchestra Recording of Beethoven's Symphony No. 8 op. 93" (2018), https:// doi.org/10.14279/depositonce-6729.

[18] "DIN IEC 60268-1: Sound System Equipment; General,” German Institute for Standardisation (1988).

[19] S. Brunner, H. -J. Maempel, and S. Weinzierl, “On the Audibility of Comb Filter Distortions," presented at the 122nd Convention of the Audio Engineering Society (2007 May), convention paper 7047.

[20] F. Brinkmann and S. Weinzierl, "AKtools-An Open Software Toolbox for Signal Acquisition, Processing, and Inspection in Acoustics," presented at the 142nd Convention of the Audio Engineering Society (2017 May), convention paper 309.

[21] "DIN 33402-2: Ergonomics - Human Body Dimensions - Part 2: Values," German national standard (2005).

[22] N. R. Shabtai, G. Behler, M. Vorländer, and S. Weinzierl "Generation and Analysis of an Acoustic Radiation Pattern Database for Forty-One Musical Instruments," J. Acoust. Soc. Am., vol. 141, no. 2, pp. 1246-1256 (2017 Feb.), https://doi.org/10.1121/1.4976071. 
[23] S. Weinzierl, M. Vorländer, G. Behler, F. Brinkmann, H. von Coler, E. Detzner, J. Krämer, A. Lindau, M. Pollow, F. Schulz, and N. R. Shabtai, "A Database of Anechoic Microphone Array Measurements of $\mathrm{Mu}$ sical Instruments" (2017 Apr.), https://doi.org/10.14279/ depositonce-5861.2.

[24] S. Weinzierl, S. Lepa, F. Schultz, E. Detzner, H. von Coler, and G. Behler, "Sound Power and Timbre as
Cues for the Dynamic Strength of Orchestral Instruments," J. Acoust. Soc. Am., vol. 144, no. 3, pp. 1347-1355 (2018 Sept.).

[25] "DEGA VA 1201: Guidelines for Implementing and Documenting Audio Productions for Scientific Applications in Acoustics" (2020), https:// doi.org/10.5281/ZENODO.3597238.

\section{THE AUTHORS}

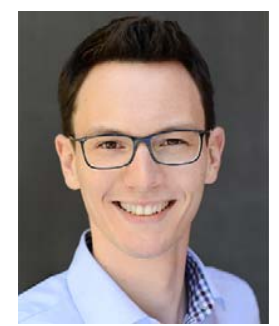

Christoph Böhm

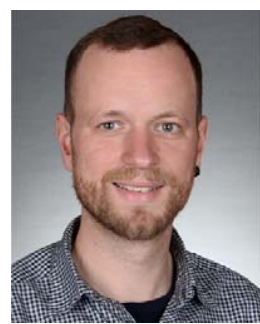

David Ackermann

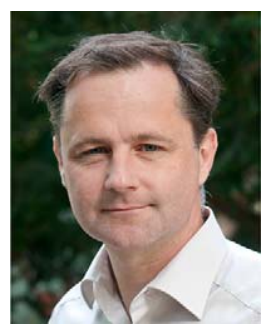

Stefan Weinzierl
Christoph Böhm received his M.Sc. degree in Audio Communication and Technology from TU Berlin, Germany, in 2015. From 2016 until the end of 2018 he was a research associate at the TU Berlin as a member of the Cluster Of Excellence Image Knowledge Gestaltung. He works on his doctoral thesis at the Audio Communication Group at TU Berlin in the field of virtual acoustics with a main focus on uncertainties in room acoustic simulation and auralization.

David Ackermann received his M.Sc. degree in Audio Communication and Technology from TU Berlin, Germany, in 2015. He has been a research associate in the Audio Communication Group at the TU Berlin since 2015, where his research is focused in the field of virtual and musical acoustics. His research includes the investigation of the time-dependent behavior of natural acoustic sound sources and their auralization in virtual acoustic environments.

Stefan Weinzierl is head of the Audio Communication Group at the Technische Universität Berlin. His research is focused on audio technology, virtual acoustics, room acoustics, and musical acoustics. With a diploma in physics and sound engineering, he received his Ph.D. in musical acoustics. He is coordinating a master program in Audio Communication and Technology at TU Berlin and has coordinated international research consortia in the field of Virtual Acoustics (SEACEN) and Music Information Retrieval (ABC_DJ). 